\title{
Serum Calcium, Magnesium, Uric Acid and C-Reactive Protein in Preeclampsia and Normal Pregnant Women \\ Mostafa A. Abdel-Hamid ${ }^{1 *}$, Abd El Moneim m. Zakaria ${ }^{1}$, Fahd A. Alomda ${ }^{1}$ and Mekky Abd El Moneim ${ }^{2}$ \\ Obstetrics \& Gynecology ${ }^{1}$, Clinical and Chemical Pathology ${ }^{2}$ Departments, \\ Faculty of Medicine, Al-Azhar University, Egypt \\ * Corresponding Author: Mostafa A. Abdel-Hamid, email: Mostafakaseb1@yahoo.com
}

\begin{abstract}
Objective: To assess and to look at serum levels of calcium, magnesium, uric acid and C-reactive protein in mild, extreme preeclamptic ladies and ordinary pregnant ladies and to connect these levels with seriousness of the ailment. Methods: This investigation was a planned observational case-control study that was led at the division of Obstetrics and Gynecology, Al-Azhar University, Maternity Hospital on 90 pregnant ladies in the third trimester of pregnancy (gestational age from 28 to 40 weeks of pregnancy) chosen from the individuals who had gone to the antenatal facility and the banquet hall in the period from January 2018 to June 2019. They were divided into 3 groups: 30 patients with serious preeclampsia, 30 patients with gentle preeclampsia and 30 normotensive ladies free of any medicinal issue (control group). The study was approved by the medical ethics committee of Al-Azhar University Hospitals and a written informed consent is obtained from all participants. Results: The mean estimations of CRP and serum uric acid were fundamentally higher in the pregnant ladies with preeclampsia than in the sound control ladies $(\mathrm{p}<0.05)$, while the mean estimations of serum calcium were altogether lower in the pregnant ladies with preeclampsia than in the solid control ladies $(\mathrm{p}<0.05)$. The mean serum magnesium didn't demonstrate critical contrasts among preeclampsia and solid ladies $(p>0.05)$. Conclusion: These discoveries bolster the speculation that hypocalcaemia, hyperuricemia and expanded C-reactive protein could be potential etiologies of preeclampsia and that they relate to the seriousness of the illness.
\end{abstract}

Keywords: Serum calcium, Serum magnesium, Serum uric acid, C-reactive protein, Preeclampsia, Normal pregnancy.

\section{INTRODUCTION}

Hypertensive issue of pregnancy influence about $10 \%$ of every single pregnant lady ${ }^{(\mathbf{1})}$ and record for in excess of 50000 maternal passing for each year ${ }^{(2)}$ and together they structure one individual from the fatal set of three, alongside discharge and contamination, that contribute significantly to maternal sickness and death rates ${ }^{(3)}$.

With hypertension, the preeclampsia disorder, either alone or superimposed on interminable hypertension, is the most hazardous ${ }^{(\mathbf{3})}$. Preeclampsia is a multisystem issue that entangles 3\%-8\% of pregnancies in Western nations and establishes a noteworthy wellspring of dreariness and mortality around the world ${ }^{(4,5)}$.

Preeclampsia (PE) is a disorder, all around characterized by the beginning of hypertension $(\geq 140 / \geq 90 \mathrm{mmHg})$ and proteinuria $(\geq 0.3 \mathrm{~g} / 24 \mathrm{~h})$ following 20 weeks of development in a formerly normotensive lady that likewise might be related with bunch, different signs and indications, and frequently with subnormal fetal development ${ }^{(6,7)}$.

Preeclampsia is best depicted as a pregnancy explicit disorder of decreased organ perfusion optional to vasospasm and endothelial actuation, described by hypertension and proteinuria that may prompt multisystem inclusion including renal, hematological, hepatic and cerebral debilitation ${ }^{(\mathbf{8}) .}$
Preeclampsia starts with lacking trophoblastic intrusion right off the bat in pregnancy, which delivers an expansion in oxidative pressure adding to the advancement of foundational endothelial brokenness in the later periods of the ailment, prompting the trademark clinical sign of preeclampsia ${ }^{(9)}$.

Raised serum uric acid levels because of diminished renal urate discharge are every now and again found in ladies with preeclampsia (6). Hyperuricemia because of oxidative pressure is known to be related with malicious consequences for endothelial brokenness, oxidative digestion, platelet adhesiveness and conglomeration (10). Subsequently raised serum uric acid is profoundly prescient of expanded danger of unfriendly maternal and fetal result ${ }^{(11)}$.

On the physiological premise, calcium assumes a significant job in muscle compression and guideline of water balance in cells. Change of plasma calcium fixation prompts the adjustment of circulatory strain. The bringing down of serum calcium and the expansion of intracellular calcium can cause a rise of circulatory strain in preeclamptic moms ${ }^{(\mathbf{1 2}, \mathbf{1 3})}$.

In perspective on the above realities this examination targets assessing serum levels of calcium, magnesium, uric acid and C-reactive protein in patients with clinical profiles of preeclampsia and in 
normotensive pregnant ladies and relating these levels with seriousness of preeclampsia.

\section{PATIENTS AND METHODS}

This examination was a planned observational case-control study that was led at the branch of Obstetrics and Gynecology, Al-Azhar University Maternity Hospital on 90 pregnant ladies in the third trimester of pregnancy (gestational age from 28 to 40 weeks of pregnancy) chose from the individuals who had gone to the antenatal center and the banquet hall in the period from January 2018 to June 2019.

\section{The study group was divided into 3 groups:}

Group 1: Consists of 30 pregnant ladies with gentle preeclampsia in the third trimester of pregnancy that was determined by last menstrual period (LMP) or first trimester ultrasound.

Group 2: Consists of 30 pregnant ladies with serious preeclampsia in the third trimester of pregnancy that was determined by last menstrual period (LMP) or first trimester ultrasound.

Group 3 (control group): comprises of 30 normotensive pregnant ladies in the third trimester of pregnancy that was determined by last menstrual period (LMP) or first trimester ultrasound.

Pregnant women eligible for the study had the following inclusion criteria:

1. Age from 18-35 years.

2. Gestational age over 28 weeks till 40 weeks.

3. Singleton pregnancy.

4. Living baby.

5. Patients with mellow or serious preeclampsia as indicated by the criteria referenced by the American College of Obstetricians and Gynecologists (ACOG) (14).

\section{(A) Diagnostic criteria of mild preeclampsia are:}

Blood weight $\geq 140 / 90 \mathrm{mmHg}$ following 20 weeks' development estimated at any rate twice 4-6 hours separated in a lady with a formerly typical circulatory strain.

Proteinuria $\geq 0.3 \mathrm{gm} / 24$ hours or $\geq 1+$ dipstick pee.

(B) Diagnostic criteria of severe preeclampsia are:

Blood weight $\geq 160 / 110 \mathrm{mmHg}$ estimated on 2 events at any rate 6 hours separated while the patient is on bed rest

Proteinuria $\geq 5 \mathrm{gm} / 24$ hours or $\geq 3+$ dipstick pee on two irregular pee tests gathered at any rate 4 hours separated

Oliguria, with discharge of under $500 \mathrm{~mL}$ of pee in 24 hours

Decreased platelet tally

Pulmonary edema or cyanosis

Impairment of liver capacities

Persistent migraine or other cerebral or visual unsettling influences

Persistent epigastric agony or right upper quadrant torment
Intrauterine development limitation (IUGR).

Pregnant women who had any of the following conditions were excluded from the study:

1. Pregnant ladies with history of any therapeutic issue, for example, fundamental hypertension, diabetes mellitus, renal infections, cardiovascular sicknesses, endocrine maladies or immune system illnesses.

2. Gestational age under 28 weeks or over 40 weeks.

3. Multi-fetal incubation.

4. Intra-uterine fetal demise.

5. Presence of inborn fetal oddities.

6. History of break of films or clinical chorioamnionitis.

\section{Study Design and ethical condideration:}

- The study was approved by the medical ethics committee of Al-Azhar University Hospitals and a written informed consent is obtained from all participants. After being informed about the aims and process of the study.

- The study procedures were free from any harmful effects on the participants as well as the service provided.

- The principal investigators have kept individual data as private information safely. There was no extra fee to be paid by the participants and the investigators covered all the costs in this regard. An Official permission was obtained from Faculty of Medicine, Al-Azhar University.

- An official permission was obtained from the Gynecology and Obstetrics Department .

- An official permission was obtained from the Institutional Research

- Approval from ethical committee in the faculty of medicine (Institutional Research Board IRB).

All individuals were conducted to:

1. Full history taking to bar the past prohibition criteria in chose cases.

2. Thorough clinical assessment including:

General assessment: incorporate appraisal of circulatory strain, beat, temperature, edema and profound ligament reflexes.

Pulse estimation:

In semi-sitting position.

Using proper sleeve size.

Patient's arm upheld and situated at level of the heart.

Listen for a stifling sound (Korotkoff's sounds stage 5).

Using mercury sphygmomanometer.

Full obstetric assessment.

3. Proteinuria appraisal:

Mild proteinuria: Protein dipstick $\geq 1+$ on $\geq 2$ midstream tests 6 hours separated.

Severe proteinuria: Protein dipstick $\geq 3+$ on $\geq 2$ midstream tests 6 hours separated.

4. Special examinations including:

Obstetric ultrasonography for appraisal of 
gestational age, biophysical profile (BPP), fetal weight and prohibition of inborn peculiarities or multi-fetal incubation.

Doppler study for the umbilical course.

5. Laboratory examinations including: Estimation of the serum levels of calcium, magnesium, uric corrosive and C-responsive protein. Other routine research facility examinations were additionally surveyed as complete blood picture, coagulation profile, kidney capacities, liver capacities, blood glucose level and 24-hours pee proteins.

6. Neonatal evaluation as respects:

Neonatal birth weight

Apgar score (1 and 5 minutes)

Neonatal emergency unit.

Specimen Collection: An example of venous blood was gotten from the patient and a coagulation was permitted to shape and withdraw. Thickened blood test was centrifugated and clear serum was gathered. Serum was put away at temperature between $2^{\circ} \mathrm{C}$ to $8^{\circ} \mathrm{C}$. Taking in thought that in the preeclamptic gathering, venous blood tests were gathered before inception of any therapeutic treatment.

\section{Test to Measure Serum Calcium:}

Principle of the test: Calcium with Arsenazo III (1,8Dihydroxy-3,6-disulpho-2,7-naphthalene-bis(azo)dibenzenearsonic corrosive), at unbiased $\mathrm{pH}$, yields a blue shaded complex. The force of the shading framed is corresponding to the calcium fixation in the example.

Reagent composition: Reagent 1: Arsenazo III reagent.

Calcium standard: $10 \mathrm{mg} / \mathrm{dl}$.

Reagent preparation: All reagents are prepared to utilize.

Assay procedure: Examine conditions:

Wavelength: $630 \mathrm{~nm}$

Reaction temperature: $37^{\circ} \mathrm{C}$

Cuvette: $1 \mathrm{~cm}$ way length

Units: $\mathrm{mg} / \mathrm{dL}$

1. It is prescribed to utilize dispensable material. If dish sets are utilized the defilement of crystal with calcium will influence the test. Utilize corrosive washed crystal or plastic cylinders.

2. Most of the cleansers and water mellowing items utilized in the research facilities contain chelating operators. A blemished flushing will discredit the methodology.

3. Use clean expendable pipette tips for its regulation.

4. CARZ 50 is extraordinarily treated monovials with $1 \mathrm{ml}$ pre-administered reagent. Simply include 25 $\mu \mathrm{L}$ test/sexually transmitted disease, hatch at room temperature for 5 minutes and suction.

\section{RESULTS}

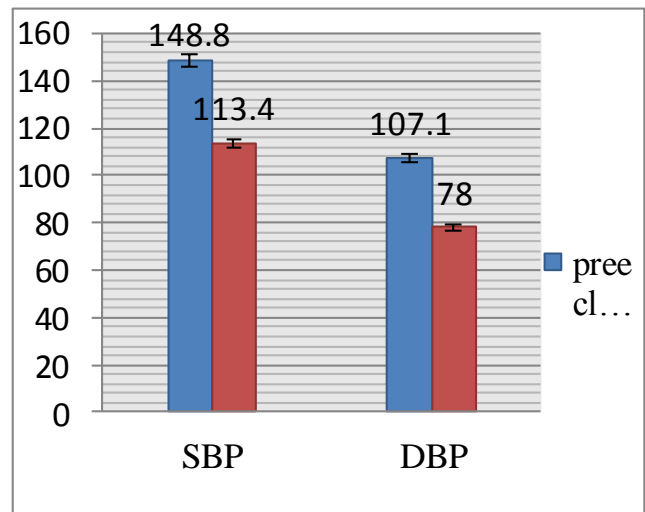

Figure (1) Mean blood pressure measurement of the studied groups.

The mean gestational age in the solid gathering was not factually fundamentally higher than in the pregnant ladies with serious preeclampsia $(\mathrm{p}<0.05)$. The mean estimations of SBP and DBP were altogether higher in the pregnant ladies with serious preeclampsia than in the pregnant ladies with gentle preeclampsia and sound pregnant ladies $(\mathrm{p}<0.05)$.

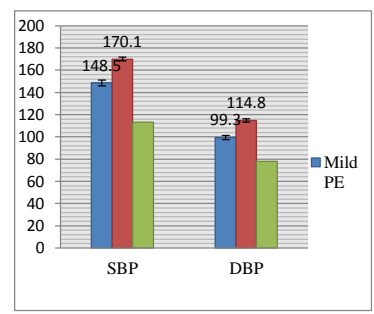

Figure (2) Mean blood pressure measurement of the studied populations according to preeclampsia (PE) severity.

The mean estimations of CRP and serum uric corrosive were fundamentally higher in the pregnant ladies with preeclampsia than in the sound control ladies $(p<0.05)$, while the mean estimations of serum calcium were altogether lower in the pregnant ladies with preeclampsia than in the solid control ladies $(p<0.05)$. The mean estimations of serum magnesium didn't indicate critical contrasts among preeclampsia and sound ladies $(\mathrm{p}>0.05)$. 


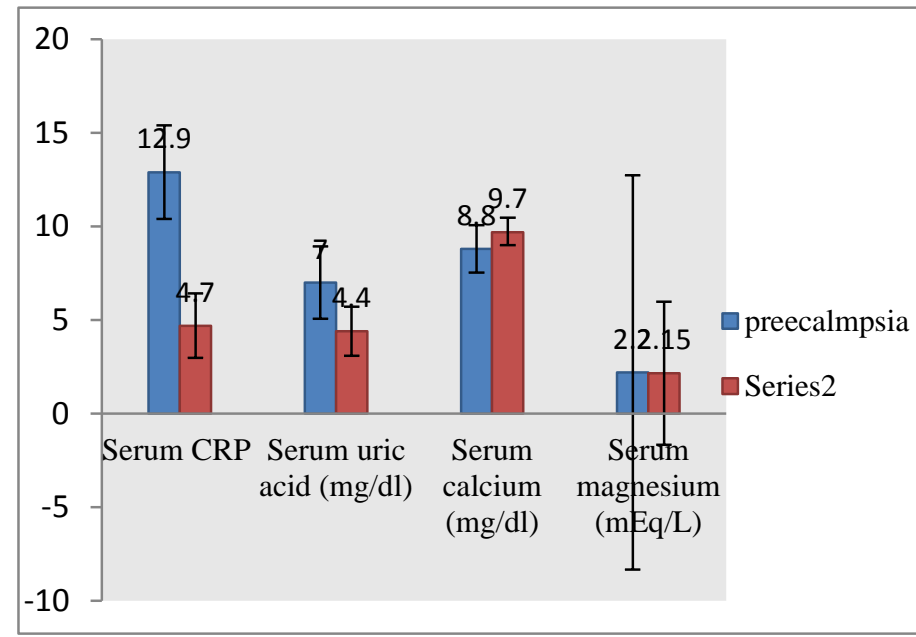

As per preeclampsia seriousness, the mean estimations of CRP and serum uric acid were fundamentally higher in the pregnant ladies with mellow and extreme preeclampsia than in the sound control ladies $(p<0.05)$, while the mean estimations of serum calcium were altogether lower in the pregnant ladies with gentle and serious preeclampsia than in the solid control ladies $(\mathrm{p}<0.05)$.

The mean estimations of serum magnesium didn't demonstrate noteworthy contrasts between mellow preeclampsia, extreme preeclampsia and solid ladies $(\mathrm{p}>0.05)$.

Figure (3): Biochemical markers of the studied patients and control group.

Table (1): Neonatal outcome in the studied patients and control group:

\begin{tabular}{|c|c|c|c|c|}
\hline Variables & Preeclampsia $(n=60)$ & Control $(n=30)$ & T test & p-value \\
\hline Neonatal birth weight (kg) & & & \multirow[b]{3}{*}{2.35} & \multirow{3}{*}{$\begin{array}{l}\mathbf{0 . 0 2} \\
\text { (S) }\end{array}$} \\
\hline Mean \pm SD & $2.8 \pm 0.42$ & $3.01 \pm 0.35$ & & \\
\hline Range & $1.9-3.5$ & $2.5-3.8$ & & \\
\hline Apgar-1 & & & \multirow{3}{*}{2.60} & \multirow{3}{*}{$\begin{array}{l}\text { 0.01 } \\
\text { (S) }\end{array}$} \\
\hline Mean \pm SD & $8.5 \pm 0.78$ & $8.9 \pm 0.44$ & & \\
\hline Range & $7.0-9.0$ & $8.0-10.0$ & & \\
\hline Apgar-5 & & & \multirow{3}{*}{1.26} & \multirow[t]{3}{*}{0.209} \\
\hline Mean \pm SD & $9.5 \pm 0.75$ & $9.7 \pm 0.61$ & & \\
\hline Range & $7.0-10.0$ & $8.0-10.0$ & & \\
\hline NICU admission & & & \multirow[t]{3}{*}{ Fisher test } & \multirow{3}{*}{$\begin{array}{l}\text { 0.012 } \\
\text { (S) }\end{array}$} \\
\hline Yes & $21(35.0 \%)$ & $3(10.0 \%)$ & & \\
\hline No & $39(65.0 \%)$ & $27(90.0 \%)$ & & \\
\hline
\end{tabular}

Table (1): demonstrates the neonatal result in the contemplated patients and control group. The mean neonatal birth weight was essentially lower in the pregnant ladies with preeclampsia than in the sound control ladies (2.8 versus 3.01, separately, $\mathrm{p}<0.05)$. As to score, the mean Apgar score at 1 moment was fundamentally lower in the patients with preeclampsia than in the solid control ladies (8.5 versus 8.9, individually, $\mathrm{p}<0.05$ ), while there was no critical contrast between the two gatherings in regards to Apgar score at 5 minutes $(\mathrm{p}>0.05)$.

Table (2): Correlations between severity of preeclampsia and studied variables:

\begin{tabular}{|c|c|c|}
\hline \multirow{2}{*}{ 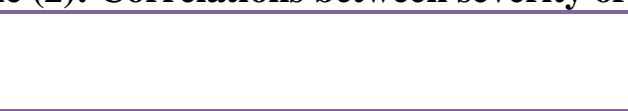 } & \multicolumn{2}{|l|}{ Severity of preeclampsia } \\
\hline & Correlation coefficient ( $r$-value) & p-value (2-tailed) \\
\hline Age (years) & -0.140 & 0.232 \\
\hline Gestational age (weeks) & -0.301 & $0.015 \quad(S)$ \\
\hline SBP & 0.956 & $<0.0001$ (HS) \\
\hline DBP & 0.963 & $<0.0001(\mathrm{HS})$ \\
\hline Serum CRP & 0.737 & $<0.0001(\mathrm{HS})$ \\
\hline Serum uric acid & 0.717 & $<0.0001$ (HS) \\
\hline Serum calcium & -0.663 & $<0.0001$ (HS) \\
\hline Serum magnesium & 0.053 & 0.675 \\
\hline Neonatal birth weight & -0.460 & $<0.0001(\mathrm{HS})$ \\
\hline Apgar score $1 \mathrm{~min}$ & -0.420 & $<0.0001$ (HS) \\
\hline Apgar score 5 min & -0.293 & $\mathbf{0 . 0 1 7} \quad$ (S) \\
\hline NICU admission & 0.223 & 0.065 \\
\hline
\end{tabular}

Table (2): demonstrates the connections between seriousness of preeclampsia and contemplated factors. There were noteworthy positive relationships between seriousness of preeclampsia and SBP, DBP, CRP, and serum uric acid. In the interim, there were noteworthy negative relationships between seriousness of preeclampsia and gestational age, serum calcium, neonatal birth weight, Apgar score 1 min and 5 min. 
Table (3): Correlations between occurrence of preeclampsia and studied variables:

\begin{tabular}{|c|c|c|}
\hline & \multicolumn{2}{|c|}{ Occurrences of preeclampsia } \\
\hline & Correlation coefficient ( $r$-value) & p-value (2-tailed) \\
\hline Age (years) & -0.161 & 0.201 \\
\hline Gestational age (weeks) & -0.319 & 0.010 \\
\hline SBP & 0.901 & $<0.0001$ (HS) \\
\hline DBP & 0.888 & $<0.0001(\mathrm{HS})$ \\
\hline Serum CRP & 0.670 & $<0.0001$ (HS) \\
\hline Serum uric acid & 0.721 & $<0.0001$ (HS) \\
\hline Serum calcium & -0.626 & $<0.0001$ (HS) \\
\hline Serum magnesium & 0.111 & 0.377 \\
\hline Neonatal birth weight & -0.299 & $0.016(\mathrm{~S})$ \\
\hline Apgar score 1 min & -0.285 & $0.022(\mathrm{~S})$ \\
\hline Apgar score 5 min & -0.153 & 0.224 \\
\hline NICU admission & 0.183 & 0.144 \\
\hline
\end{tabular}

Table (3): demonstrates the relationships between event of preeclampsia and examined factors. There were critical positive relationships between event of preeclampsia and SBP, DBP, CRP and serum uric corrosive.

\section{DISCUSSION}

The point of the investigation was to assess and to think about degrees of serum calcium, magnesium, uric corrosive and C-reactive protein in pregnant patients with preeclampsia and typical pregnant ladies and to assess and to look at the neonatal result in regards to neonatal birth weight, Apgar score and neonatal emergency unit in both pregnant patients with preeclampsia and normotensive control gathering .

This investigation was an imminent observational case-control study that was directed at the Department of Obstetrics and Gynecology, Faculty of Medicine, Al-Azhar University on 90 pregnant ladies in the third trimester of pregnancy (gestational age from 28 to 40 weeks of pregnancy) chosen from the individuals who had gone to the antenatal center and the banquet hall in the period from January 2018 to June 2019.

\section{following:}

The main results of the study were as

The present examination, the mean age of the considered groups was coordinated with no measurably huge contrasts $(\mathrm{p}>0.05)$. Gestational age of the considered patients and controls was run from 28 to 40 weeks, the distinction between the two groups was immaterial ( $p>0.05)$. Additionally, according to preeclampsia seriousness, the mean age didn't indicate huge contrasts between gentle preeclampsia, extreme preeclampsia and sound ladies $(p>0.05)$. The mean gestational age in the sound group was not factually essentially higher than in the pregnant ladies with serious preeclampsia $(\mathrm{p}<0.05)$. The mean estimations of SBP and DBP were altogether higher in the pregnant ladies with extreme preeclampsia than in the pregnant ladies with gentle preeclampsia and solid pregnant ladies $(\mathrm{p}<0.05)$

This study is coincided with that done by Kameswaramma ${ }^{(15)}$, who found that the mean gestational age was not essentially unique between the typical pregnant ladies and the preeclamptic bunch .

In the present work, the mean estimations of systolic circulatory strain (SBP) and diastolic pulse (DBP) were essentially higher in the pregnant ladies with preeclampsia than in the sound control ladies $(\mathrm{p}<0.05)$.

This was coincided with a cross sectional case control study that was led at Department of Obstetrics and Gynecology at Narayana Medical College Hospital. The investigation was completed between June 2012 and July 2013. The study comprised of 50 pregnant ladies, 25 preeclampsia and 25 typical pregnant ladies as control. All ladies had gestational ages of 23-37 weeks. The consequences of this investigation demonstrated that the mean systolic circulatory strain was essentially higher in ladies with preeclampsia than in ordinary pregnant ladies $(\mathrm{p}=0.01)$. Mean diastolic circulatory strain was likewise altogether higher in ladies with preeclampsia than in typical pregnant ladies $(\mathrm{p}=0.03)^{(\mathbf{1 5}) \text {. }}$

In the present work, according to preeclampsia seriousness, the mean estimations of serum magnesium didn't demonstrate noteworthy contrasts between mellow preeclampsia, extreme preeclampsia and solid ladies ( $\mathrm{p}>0.05)$.

The present finding was likewise the discoveries of previous study done by Roy $\boldsymbol{e t}$ al. ${ }^{(\mathbf{1 6})}$ serum magnesium level was $3.37 \pm 2.05 \mathrm{mg} / \mathrm{dl}$ in preeclamptic group and $2.87 \pm 1.38 \mathrm{mg} / \mathrm{dl}$ in typical pregnant ladies; the level did not vary essentially 
between the subject of preeclampsia and ordinary pregnant ladies $(\mathrm{p}=0.153)$. Additionally, revealed Findings of their examination propose that serum magnesium has no relationship with preeclampsia .

In the present examination, according to preeclampsia seriousness, the mean estimations of serum uric acid were altogether higher in the pregnant ladies with mellow and extreme preeclampsia than in the sound control ladies $(\mathrm{p}<0.05)$.

In an examination done by Hawkins et al. ${ }^{(18)}$ there was noteworthy increment in the degrees of serum uric acid in preeclampsia (PE) and they recommended that hyperuricemic levels are autonomously and altogether connected with danger of unfriendly results (20). Seriousness of preeclampsia increments with expanding uric acid focus ${ }^{(19) .}$

Another investigation done by Saleh et al. ${ }^{(21)}$ who discovered critical increment in the serum uric acid levels in patients with preeclampsia and expressed that it could be a decent indicator of maternal ailment movement and fetal outcome ${ }^{(21)}$

Another study done by Williams and Galerneau ${ }^{(22)}$ demonstrated that serum uric acid was a poor indicator of preeclampsia .

Diwan et al ${ }^{(23)}$ expressed that serum uric acid levels are fundamentally brought up in preeclampsia than ordinary pregnancy and there is a high positive connection with the ailment seriousness in connection to hypertension ${ }^{(23)}$. Additionally, Brainbridge et al. (17) expressed that seriousness of preeclampsia increments with expanding uric acid focus, which is in concurrence with our investigations.

In the present examination, according to preeclampsia seriousness, the mean estimations of CRP were essentially higher in the pregnant ladies with mellow and extreme preeclampsia than in the solid control ladies $(\mathrm{p}<0.05)$.

Additionally the present investigations coincided with that finding revealed by (24) who demonstrated that $\mathrm{C}$-reactive protein was $10.28 \pm 7.25$ $\mathrm{mg} / \mathrm{mL}$ in mellow PE and $10.94 \pm 6.32 \mathrm{mg} / \mathrm{mL}$ in extreme $\mathrm{PE}$ and $3.45 \pm 1.71 \mathrm{mg} / \mathrm{mL}$ in normotensive group, which was essentially higher than control group $(\mathrm{P}=0.000)$. In the present work, our finding coincided with the discoveries of past investigation done by Mihu et al. ${ }^{(25)}$ who detailed that in preeclampsia, a higher fundamental fiery status was found contrasted with ordinary pregnancy. Gestational age during childbirth, fetal weight, and Apgar score were altogether lower in the gathering with preeclampsia contrasted with typical pregnancy ${ }^{(25}$.

In the present work, there were noteworthy positive connection between seriousness of preeclampsia and CRP, which was in concurrence with finding of past investigation conducted by
Mirzaie et al. ${ }^{(25)}$. Their cross-sectional study was led in three groups of ladies. Group1 composed of 43 ladies with mellow preeclampsia at the hour of affirmation; Group 2 included 43 ladies with serious preeclampsia and Group 3 composed of 43 solid normotensive ladies in the third trimester of their pregnancy. All groups had gestational ages of 28-40 weeks, not in labor and singleton. They found that assurance of serum CRP levels in the third trimester pregnant ladies demonstrated of extraordinary incentive in anticipating the forecast of preeclampsia. They reasoned that CRP levels related emphatically with the seriousness of malady ${ }^{\mathbf{2 6}}$ ).

Additionally, this examination in concurrence with study directed by Begum et al. ${ }^{(27)}$. Mean and standard deviation for CRP, systolic and diastolic circulatory strain, were exceptionally huge $(\mathrm{p}<0.000)$ in preeclamptic ladies as contrast with control group. Mean and standard deviation of CRP $(10.52 \pm 10.24)$ in preeclamptic ladies was exceptionally huge $\mathrm{P}<0.000$ when contrasted and control (5.10 \pm 6.20$)$. Also, presumed that CRP demonstrates noteworthy relationship with systolic and diastolic circulatory strain and is a superior indicator of PE and eclampsia (27).

In 2010, Ertas $\boldsymbol{e t} \boldsymbol{a l} .{ }^{(28)}$ in the wake of contemplating groups of patients stratified by seriousness of malady as mellow and extreme preeclamptics, reasoned that raised CRP level is a valuable parameter in seriousness of preeclampsia ${ }^{(28)}$

Be that as it may, the present outcome is opposing to certain investigations which did not locate a critical job of CRP in pregnancies convoluted by preeclampsia when contrasted with normotensive pregnant ladies ${ }^{(29,30)}$. Contrasts in test size, timing of test group the hidden qualities of study populaces and CRP location strategy pursued by these investigations may represent the fluctuation in results crosswise over examinations .

In the present examination, the mean neonatal birth weight was altogether lower in the pregnant ladies with preeclampsia than in the solid control ladies ( 2.8 versus 3.01 , separately, $\mathrm{p}=0.02$ ) and there were critical negative connections between event of preeclampsia and gestational age, serum calcium, neonatal birth weight and Apgar score $1 \mathrm{~min}$.

A planned report was conveyed by Kishwara et al. ${ }^{(31)}$ of which 30 having typical uncomplicated pregnancies (considered as control group or Group A and another 30 from pregnancies convoluted by preeclampsia (considered as preeclampsia group or group B), where the patients were normotensive already. Pregnant ladies were chosen between 35-40 weeks of gestation. In this examination, the mean birth weight of the neonate was $2.80 \pm 0.27 \mathrm{~kg}$ and $2.26 \pm 0.41$ 
$\mathrm{kg}$ in group A and group B individually. The mean distinction between the two groups was noteworthy at $\mathrm{p}<0.001$. This investigation had demonstrated that neonatal birth weight had been decreased in pregnancies muddled by preeclampsia ${ }^{(31)}$ and this was in concurrence with the aftereffects of our examination .

In an study done by Mayhew et al. ${ }^{(32)}$ they contemplated placental morphology in pregnancies confused by preeclampsia with or without intrauterine development confinement and saw that fetal loads were decreased in every single confounded pregnancy however just intrauterine development limitation was joined by an altogether littler placenta ${ }^{(32) .}$

As to score in the present investigation, the mean Apgar score at 1 moment was essentially lower in the patients with preeclampsia than in the solid pregnant ladies (9.5 versus 9.7, individually, $\mathrm{p}=0.023$ )

In the study done by Kishwara et al. ${ }^{(31)}$ it was discovered that the mean Apgar score of the neonate at one moment was $9.00 \pm 1.02$ and $8.40 \pm 0.93$ in group A (normal uncomplicated pregnancies considered as control group) and group B (preeclampsia group ) separately. Factual investigation between the two groups was noteworthy as $\mathrm{p}<0.05$. This was in concurrence with that obtained in our work regarding to Apgar score at 1-minute ${ }^{(31)}$.

A case-control study conducted by ElMoselhy et al. ${ }^{(33)}$ which included 100 pregnant ladies with preeclampsia as cases and 100 pregnant ladies with sound uncomplicated pregnancy as controls. Pregnant ladies were chosen over 33 weeks of gestation. They saw that the 1-and 5-minutes Apgar scores in the neonates of PE cases were lower contrasted with controls. This coincided with our results as respects the 1-minute Apgar score yet dissimilar to the 5-minutes Apgar score in our examination where there was no huge contrast between both contemplated groups $(\mathrm{p}>0.05)$.

In the present work, there was measurably critical higher level of neonatal admission to neonatal emergency unit in preeclampsia group than in charge group (35\% versus $10 \%$, individually, $\mathrm{p}=0.012)$.

A cross-sectional similar study that was conveyed by Ayaz et al. $^{(34)}$. An aggregate of 1039 patients were conceded for conveyances during this period, 73 cases affirmed of preeclampsia (at term, i.e., 37 finished weeks) were conceded during study period, alongside 73 typical subjects as control (gestational age coordinated and no proof of preeclampsia). The investigation demonstrated that there was high requirement for admission to NICU $(26.02 \%)$ in cases contrasted with controls $(9.5 \%){ }^{(34)}$ and this was in concurrence with the discoveries of our examination .
The present work demonstrates that the mean estimations of serum CRP and serum uric acid were essentially higher in the pregnant ladies with preeclampsia than in the sound control ladies $(\mathrm{p}<0.0001)$, while the mean estimations of serum calcium were altogether lower in the pregnant ladies with preeclampsia than in the solid control ladies $(p<0.0001)$. The mean serum magnesium didn't demonstrate huge contrasts between pregnant ladies with preeclampsia and sound control ladies ( $p>0.05$ ). These discoveries bolster the theory that hypocalcaemia, hyperuricemia and expanded Creactive protein are potential causes and results of preeclampsia. Likewise, these discoveries bolster that expanded serum uric acid and serum CRP and diminished serum calcium connect to seriousness of preeclampsia.

\section{CONCLUSION}

Preeclampsia is a pregnancy-explicit intricacy establishing a noteworthy reason for maternal and fetal grimness and mortality. The early analysis of serious preeclampsia is significant to limit maternal and fetal entanglements.

\section{REFERENCES}

1. Steegers EA, von Dadelszen P, Duvekot JJ et al. (2010): Preeclampsia.Lancet,376 (9741):631644.

2. Khan K, Woidylo P, Gulmezoglu AM et al. (2006): WHO analysis of causes of maternal death: a systematic review.Lancet, 367(9516):1066-1074.

3. Cunningham FG, Veno KJ, Bloom SL et al. (2010): Pregnancy hypertension. Williams Obstetrics, 23rd edition, New York, McGraw-Hill.

4. Carty DM, Delles C and Dominiczak AF (2009): Preeclampsia and future maternal health. J Hypertens., 28:1349-1355.

5. Duley L (2009): The global impact of preeclampsia and eclampsia. Semin Perinatol. ,33(3):130-137.

6. Cunningham F, Kenneth J, Steven LB et al. (2005): Hypertensive disorder in pregnancy, from Williams Obstetrics, 22nd edition, New York, McGraw-Hill.761808.

7. Shamshiraj AA, Paidas $M$ and Krikun G (2012): Preeclampsia, hypoxia, thrombosis and inflammation. J Pregnancy, 2012:374047.

8. Tomlinson TM and Sadovsky Y (2010): Pregnancy: preeclampsia and eclampsia.In: Kollef MH,Bedient TJ, Isakow W,Witt CA,editors. The Washington Manual of Critical Care, 8th ed. NewYork : Wolters-Lippincott Williams \& Wilkins.

9. Valenzuela FJ, Pérez-Sepúlveda A, Torres MJ et al. (2011):Pathogenesis of preeclampsia: the genetic component. J Pregnancy, 632-732.

10. Nadkar MY and Jain VI (2008): Serum uric acid in acute myocardial infarction. JAPI., 56(10):759-762. 
11. Hawkins TL A, Roberts JM, Mangos GJ et al. (2012): Plasma Uric Acid remains a marker of poor outcome in hypertensive pregnancy: A Retrospective cohort study. BJOG., 119:484-492.

12. Kisters K, Barenbrock M, Louwen F et al. (2000): Membrane, intracellular, and plasma magnesium and calcium concentrations in preeclampsia. Am J Hypertens., 13:765-9.

13. Ray J, Vasishta K, Kaur S et al. (1999): Calcium metabolism in preeclampsia. Int $\mathbf{J}$ Gynaecol Obstet.,66:245-50.

14. Vilchez G, Dai J, Lagos M et al. (2018). Maternal side effects \& fetal neuroprotection according to body mass index after magnesium sulfate in a multicenter randomized controlled trial. The Journal of MaternalFetal \& Neonatal Medicine, 31(2): 178-183.

15. Kameswaramma $K$ (2014): Estimation of $C$ - reactive protein, magnesium and uric acid levels in preeclampsia patients in comparison with normal pregnant women. Sch. J. App. Med. Sci. ,2(2B):628-632.

16. Roy H L, Nargis S, Mahmud S H et al. (2017): Evaluation of serum magnesium level in preeclampsia. Bangladesh Journal of Medical Biochemistry, 10(1), 1015.

17. Brainbridge SA, Roberts JM (2008). Uric acid as a pathogenic factor in preeclampsia. Placenta, 29:67-72.

18. Khaliq O P, Konoshita, Moodley J et al. (2018): The role of uric acid in preeclampsia: Is uric acid a causative factor or a sign of preeclampsia? Current hypertension reports, 20(9): 80.

19. Schmella M J, Clifton R G, Althouse A D et al. (2015): Uric acid determination in gestational hypertension: is it as effective a delineator of risk as proteinuria in high-risk women? Reproductive Sciences, 22(10): 1212-1219.

20. Hawkins TL, Roberts JM, Mangos GJ et al. (2012): Plasma uric acid remains a marker of poor outcome in hypertensive pregnancy: a retrospective cohort study. BJOG. ;119(4):484-492.

21. Saleh F, Shukar-ud-Din S, Soomro N (2010): Serum uric acid as predictor model for pre-eclampsia. Pak $\mathbf{J}$ Surg., 26(3):246-251.

22. Williams KP ,Galerneau F (2002): The role of serum uric acid as a prognostic indicator of the severity of maternal and fetal complications in hypertensive pregnancies. J Obstet Gynaecol Can., 24: 628-32.

23. Diwan J, Shah $\mathrm{C}$, Dixit $\mathrm{R}$ et al. (2011): A Comparative Study of Serum Uric Acid Level in
Normal Pregnancy, and Pregnancy Induced Hypertension. Int J Med Public health, 1(1):39-41.

24. Sharmin S, Chy S, Alam D et al. (2016): Association of Serum C-reactive Protein in Preeclampsia and its Effect on Fetal Birth Weight A Case Control Study. Bangladesh Journal of Obstetrics \& Gynaecology, 31(2), 75-80.

25. Mihu D, Razvan C, Malutan A et al. (2015): Evaluation of maternal systemic inflammatory response in preeclampsia. Taiwanese Journal of Obstetrics and Gynecology, 54(2): 160-166.

26. Mirzaie F, Rahimi-Shorbaf F, Kazeronie A (2009): Association of maternal serum C-reactive protein levels with severity of preeclampsia. Acta Medica Iranica. 47(4):293-296.

27. Begum G, Zaman N, Khan $\mathrm{R}$ et al. (2017): Correlation of C-reactive protein with severity of preeclampsia. KJMS, 10(3): 337.

28. Ertas IE, Kahyaoglu S, Yilmaz B et al. (2010): Association of maternal serum highly sensitive Creactive protein level with body mass index and severity of preeclampsia at third trimester. J Obstet Gynaecol Res., 36:970-7.

29. Stefanovic M, Vukomanovic P, Milosavljevic $M$ et al. (2009): Insulin resistance and C-reactive protein in preeclampsia. Bosn J Basic Med Sci. 9:235-8.

30. Kristensen $\mathrm{K}$, Wide-Swensson $\mathrm{D}$, Lindstrom $\mathrm{V}$ et al. (2009): Serum amyloid and C-reactive protein in normal pregnancy and preeclampsia. Gynecol Obstet. Invest., 67:275-80.

31. Kishwara S, Tanira S, Omar E et al. (2011): Effects of preeclampsia on perinatal outcome- A study done in the specialized Urban Hospital set up in Bangladesh. Bangladesh Medical Journal,40(10):33-36.

32. Mayhew TM, Ohadike C, Baker PN et al. (2003): Stereological investigation of placental morphology in pregnancies complicated by preeclampsia with and without intrauterine growth restriction. Placenta, 24:219-26.

33. El-Moselhy EA, Khalifa HO, Amer SM et al. (2011): Risk factors and impacts of preeclampsia: An epidemiological study among pregnant mothers in Cairo, Egypt. Journal of American Science, 7(5):311323.

34. Ayaz A, Mohammed T, Hussain SA et al. (2009): Neonatal outcome in preeclamptic patients. J Ayub Med Coll Abbottabad, 21(2):53-5. 